\title{
Há certeza na incerteza?
}

\section{Is there certainty in uncertainty?}

\author{
Wilton Barroso \\ Professor do Departamento de Filosofia e do Programa de Pós-graduação em \\ Literatura/Universidade de Brasília. \\ wbf@unb.br
}

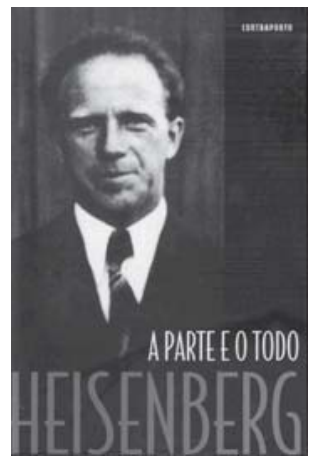

HEISENBERG, Werner. A parte e o todo. Trad., Vera Ribeiro. Rio de Janeiro: Contraponto, 2008. 286p.

Sem dúvida o surgimento da mecânica quântica no início do $\checkmark$ século XX provocou um duplo caminho: o da consolidação científica da nova disciplina e o da colocação de seus fundamentos filosóficos na cultura em geral. Esse duplo caminho foi muitas vezes percorrido de modo simultâneo, já que, como processo, realizou um amplo e novo desenho na cultura, provocado pela chegada do conjunto de paradigmas que constitui a mecânica quântica. Marcou o desenvolvimento da pesquisa cientítica e tecnológica, produziu novas(velhas) tensões com a religião, a política, a ética, a moral e com a cultura de modo geral. Recolocou, ainda, novas bases para a relação de arte e ciência. Longo e efervescente processo que representa, em grande parte, o solo cultural da primeira metade do século passado.

Muitos cientistas foram relevantes nesse processo de consolidação científica da nova disciplina e de colocação de seus fundamentos filosóficos na cultura em geral. Entre eles estão nomes como Albert Einstein (1879-1955), Niels Bohr (1885-1962), Max Planck (1858-1947), Paul Dirac (1902-1984), Enrico Fermi (1901-1954), Wolfgang Pauli (1900-1958). Como é amplamente sabido, a ciência é empreendimento coletivo. Assim, das conversas, das controvérsias e dos debates entre esses atores emergiu uma das mais importantes novidades científicas do século XX, responsável direta por grande parte das transformações tecnológicas que nos circundam - a mecânica nova. Alguns desses atores foram levados a interagir com outras disciplinas; era preciso colocar a mecânica quântica no conjunto dos saberes novos. Isso os levou a interagir com a filosofia, a religião e, às vezes, com a política. Afinal, aquilo que durante séculos era preciso, exato e previsível transformava-se em relativo, incerto. Muito havia para rediscutir, e o debate, no nível da fundamentação, persiste nos dias de hoje, embora com menor intensidade (Bitbol, 1996).

Um desses atores foi o físico alemão Werner Karl Heisenberg, nascido em Würzburgo, em 1901, falecido em Munique, em 1976, e um dos fundadores da mecânica quântica. Formulou, em 1925, uma teoria de matrizes ou mecânica matricial, que possui equivalência formal com a equação de Schrödinger, que é a equação fundamenal da mecânica quântica. 
Sua contribuição é considerada o primeiro desenvolvimento formal da então emergente teoria quântica. Em 1927, quando era professor em Leipzig, formulou o célebre princípio da incerteza, que hoje leva seu nome. Nas formulações clássicas, uma partícula tinha posição e momento definidos, de sorte que a qualquer momento poder-se-ia obter esses parâmetros em qualquer sistema mecânico. No entanto, Heisenberg mostra que em um sistema quântico, dadas as suas condições físicas, a probabilidade de se encontrarem a posição e o momento de uma partícula quântica é muito menor do que um, ou seja, muitíssimo improvável. Sua formulação matemática é chamada de relação de incerteza, daí a denominação atual, princípio de incerteza de Heisenberg (Leite Lopes, 1967). Ele expressa que a natureza de uma medida, sobretudo as que efetuam duas medidas simultâneas, sofre sérias reformulações no contexto da mecânica quântica. Determinar um observável, entretanto, exige a preparação adequada de todo o aparato de medição, de maneira que se possa obter uma coleção de valores do conjunto dos entes do sistema. Pelo menos teoricamente (Gedankenexperiment) deve haver essa possibilidade, ou seja, uma preparação capaz de medir tal grandeza (observável); de outra forma seria impossível determiná-la naquelas condições do experimento. No redesenho epistemológico em que emerge a mecânica quântica, há um novo papel da teoria que formula medições probabilísticas fundamentais. O advento do inexato (aproximado), em lugar do exato (preciso), está na base da teoria quântica, e isso alimentou e de certa forma ainda alimenta o debate filosófico, independentemente do desenvolvimento da disciplina (Holton, 1978). Muitas outras contribuições formais foram feitas por Heisenberg, Prêmio Nobel em 1932, embora ele se tenha tornado célebre, sem dúvida, devido ao princípio que leva seu nome.

A bela tradução do que poderíamos chamar de biografia intelectual de Werner Heisenberg, já em sua quarta edição, permite de modo bastante original ao leitor entrar num contexto em que se discutia tanto a formulação de uma teoria quanto seu lugar na cultura. É verdade que o texto carece de mais detalhamento físico-matemático, o que por certo facilitaria a comprensão de alguns (mas o tornaria inacessível a outros). Decerto a escolha do autor visa a alcançar um número maior de leitores. Ele precisava mostrar o solo cultural em que brotou a mecânica quântica e não apenas responder aos questionamentos de outras áreas do saber. A importância da mecânica clássica para a cultura moderna era a possibilidade de formulação da racionalidade. Mudar de paradigma implica falar a respeito de uma nova racionalidade, recompor as relações filosóficas e culturais.

Curiosamente o texto inicia e conclui falando em Platão, como se o autor quisesse começar e terminar no mesmo ponto, tal como um elétron no átomo de hidrogênio. Muito interessante também é o recurso à teoria do conhecimento de Kant, com a qual examina a possibilidade epistemológica para a fundamentação kantiana da mecânica quântica.

Visto em seu conjunto, o livro expõe as reflexões do autor sobre a emergência da teoria quântica e seus debates, e os diálogos dessa teoria com a filosofia, a política e a religião, provando que há vida além do Qualis. Mostrando-se homem de ação diante de seu tempo, Werner Heisenberg deixa agudo testemunho da política e da vida intelectual da Alemanha durante a ascensão, o apogeu e a derrocada do nazismo. Fascina sua sensibilidade fina para o debate, assim como sua percepção aguda da complexidade do tema. 
Wilton Barroso

\section{REFERÊNCIAS}

BITBOL, Michel.

Mécanique quantique: une introduction philosophique. Paris: Flamarion. 1996.

HOLTON, Gerard.

Scientif imaginations. Cambridge: Cambridge University Press. 1978.

LOTE LOPE, José.

Fondements de la phyque atomique. Paris: Hermann. 1967. 